\title{
PALM-COEIN classification system of FIGO vs the classic terminology in patients with abnormal uterine bleeding
}

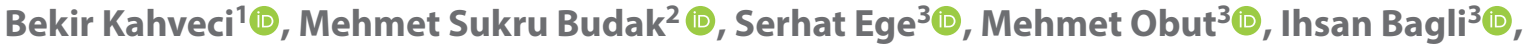 \\ Süleyman Cemil Oğlak ${ }^{3}$, Mehmet Ali Vardar ${ }^{1}$ \\ ${ }^{1}$ Cukurova University, Adana, Turkey \\ ${ }^{2}$ Dicle University, Diyarbakir, Turkey \\ ${ }^{3}$ Health Sciences University, Gazi Yasargil Training and Research Hospital, Diyarbakir, Turkey
}

\begin{abstract}
Objectives: To evaluate the FIGO's novel classification system versus the classic terminology in patients with abnormal uterine bleeding.

Material and methods: A retrospective study was carried out between August 2015 and September 2019 in the Health Sciences University Gazi Yaşargil Training and Research Hospital. The pathology reports of the patients were classified according to the PALM-COEIN method and were compared with classical terminology. The operated patients with fibroids reported in the pathology results were classified as subgroups of fibroids.

Results: Evaluation was made of a total of 515 women with abnormal uterine bleeding. According to the classical terminology, 137 (26.6\%) patients were defined with hypermenorrhea, 74 (14.4\%) with menorrhagia, 57 (11.1\%) with metrorrhagia, and 246 (47.8\%) with menometrorrhagia. In the PALM-COEIN classification system, polyps were determined in 84 (16.3\%) cases, adenomyosis in 228 [diffuse adenomyosis:196 (38.1\%), local adenomyosis:32 (6.2\%)], leiomyoma in 386 [submucous:161 (31.1\%), other types: 225 (43.9\%)], and malignancy and hyperplasia in 47 (9.1\%).

Conclusions: The classical terminology for abnormal uterine bleeding is insufficient in terms of etiological pathologies in non-pregnant women of reproductive age. The widespread use of this novel system for the abnormal uterine bleeding classification will provide a more useful communication between physicians and researchers.
\end{abstract}

Key words: abnormal uterine bleeding; menstrual disorders; PALM-COEIN classification; classic terminology

Ginekologia Polska 2021; 92, 4: 257-26

\section{INTRODUCTION}

Abnormal uterine bleeding (AUB) is one of the most widespread gynecological symptoms as uterine hemorrhage which is different from normal menstruation in non-pregnant women of reproductive age [1]. The prevalence of AUB has been reported to be $11-15 \%$ in non-pregnant women of reproductive age [2].

A large number of terms are used to define the symptoms, signs and causes of AUB, like menorrhagia, metrorrhagia, hypermenorrhea, menometrorrhagia, polymenorrhea and dysfunctional uterine bleeding. However, there has been an update to standardize descriptive terms, and menorrhagia, metrorrhagia, and oligomenorrhea have been replaced with the terminology of heavy menstrual bleeding (HMB), intermenstrual bleeding, and unscheduled bleeding or breakthrough bleeding with the use of hormone medication [3]. HMB is defined as an increase in the amount of menstrual bleeding that may affect physical, emotional and social quality of life. It can be objectively described by a drop in hemoglobin and the number of menstrual products used, such as tampons or pads per day [4].

This heterogeneity in the definitions of terminology, etiology and AUB causes confusion when comparing clinical treatment outcomes. Therefore, there has been seen to be a need for a standard, structured and consistent classification for the underlying etiology of AUB. The development of a useful and universally accepted classification system for AUB has been remarkable for a long time, because the classical terminology defining AUB contains terms that are not related to a particular pathological process [5]. 
As a result of these concerns, the International Federation of Gynecology and Obstetrics (FIGO) improved a novel classification system in 2011 to standardize AUB terminology, management and diagnosis [6]. There are nine considerable categories, which are adjusted according to the acronym: Polyp Adenomyosis Leiomyoma Malignancy and hyperplasia-Coagulopathy Ovulatory dysfunction Endometrial latrogenic Not yet classified. The "PALM" group includes structural pathologies that can be measured visually using imaging techniques or histopathology, while the "COEIN" group refers to non-structural pathologies that cannot be identified by imaging or histopathology.

The American College of Obstetricians and Gynecologists has proposed classifying AUB according to this novel system [1]. This system is a practical, consistent classification system designed for understanding and increasing knowledge of AUB, and facilitating agreement between clinicians $[7,8]$. A previous study identified several etiological factors responsible for AUB according to the PALM-COEIN classification among women undergoing hysterectomy, and concluded that this new classification is useful for comparative and epidemiological studies [9].

Even though some societies have established their own guidelines for the diagnosis and management of AUB according to the novel this classification system, it is hard to classify AUB for patients with leiomyoma as outpatients in many low-income countries [10]. There has also been shown to be no clear terminology and consensus classification for adenomyosis, which is among the causes of AUB [11].

The aim of this study was to evaluate whether the FIGO PALM-COEIN classification system is more effective than classical terminology in patients with AUB.

\section{MATERIAL AND METHODS}

This cross-sectional study was conducted between August 2015 and September 2019 at the Health Sciences University Gazi Yaşargil Training and Research Hospital. A retrospective evaluation was made of the files of patients who underwent surgeries such as hysterectomy, myomectomy and polypectomy due to AUB. Approval for the study was obtained from the Institutional Ethics Committee (Number: 2019/348). Informed consent was not obtained from the patients due to the retrospective nature of the study.

A normal menstrual cycle was described as a period of 24-38 days, lasting 4-8 days, with an average amount of bleeding of $35 \mathrm{~mL}$ and no significant changes from cycle to cycle as per FIGO guidelines. AUB was described as bleeding from the uterine corpus that occurred with abnormal regularity, volume, frequency or duration when there is no pregnancy [12].

Patient with pregnancy-related bleeding, popstmenopausal bleeding, cervix or lower genital system bleeding, suspected or diagnosed cervical carcinoma were excluded. Each patient was examined with physical examination and pelvic ultrasonography. Data were collected on patient age, parity, body mass index (BMI), and causes of AUB according to classic terminology. In addition, analysis was performed to obtain reports of surgery and pathology results for structural pathologies that were then classified according to the PALM group. Adenomyosis was divided into local and diffuse subgroups. The size, number and location of fibroids obtained from the pathology results of the operated patients were recorded and classified as a subgroup.

\section{Statistical analysis}

All statistical analyses were performed using IBM SPSS 20 software (IBM Corp. Released 2011. IBM SPSS Statistics for Windows, Version 20.0. Armonk, NY, USA). Descriptive statistics were stated as mean \pm standard deviation (SD), minimum and maximum values, number (n) and percentage (\%).

\section{RESULTS}

In this study period, 620 hysterectomies, 34 myomectomies, and 36 polypectomies were performed for AUB. Of these, 515 women [465 (90.3\%) hysterectomy, 24 (4.7\%) myomectomy and 26 (5.0\%) polypectomy] with appropriate data were determined and included. The distribution of all the patients diagnosed with AUB during the study period is summarized in Figure 1.

The mean age of the patients was $46.3 \pm 6.3$ years, mean parity was $4.2 \pm 1.6$ and mean BMI was $29.4 \pm 4.2$. According to the classical terminology, 137 (26.6\%) patients were diagnosed with hypermenorrhea, 74 (14.4\%) with menorrhagia, 57 (11.1\%) with metrorrhagia, 246 (47.8\%) with menometrorrhagia. According to the PALM-COEIN classification system, polyps were determined in $84(16.3 \%)$ cases, adenomyosis in 228 (44.3\%) [diffuse adenomyosis $\left(A_{D}\right)$ and local adenomyosis $\left(A_{L}\right)$ ], leiomyoma in $386(75 \%)$ [submucous leiomyoma $\left(\mathrm{L}_{S M}\right)$ and others leiomyoma $\left.\left(\mathrm{L}_{\mathrm{OT}}\right)\right]$, and malignancy and hyperplasia in 47 (9.1\%).

Of the 137 patients with hypermenorrhea, a significant part of these are leiomyoma, of the 74 patients with menorrhagia and of the 57 patients with metrorrhagia, a majority of these are leiomyoma, of the 247 patients with menometrorrhagia, a large part of these are leiomyoma and then adenomyosis according to the PALM-COEIN system (Tab. 1).

Overall, 386 patients underwent surgery for leimyoma, and according to the sub-classification, 65 (16.8\%) of these had submucous myoma, and the remaining $321(83.2 \%)$ patients had other types of myoma (Tab. 2). 


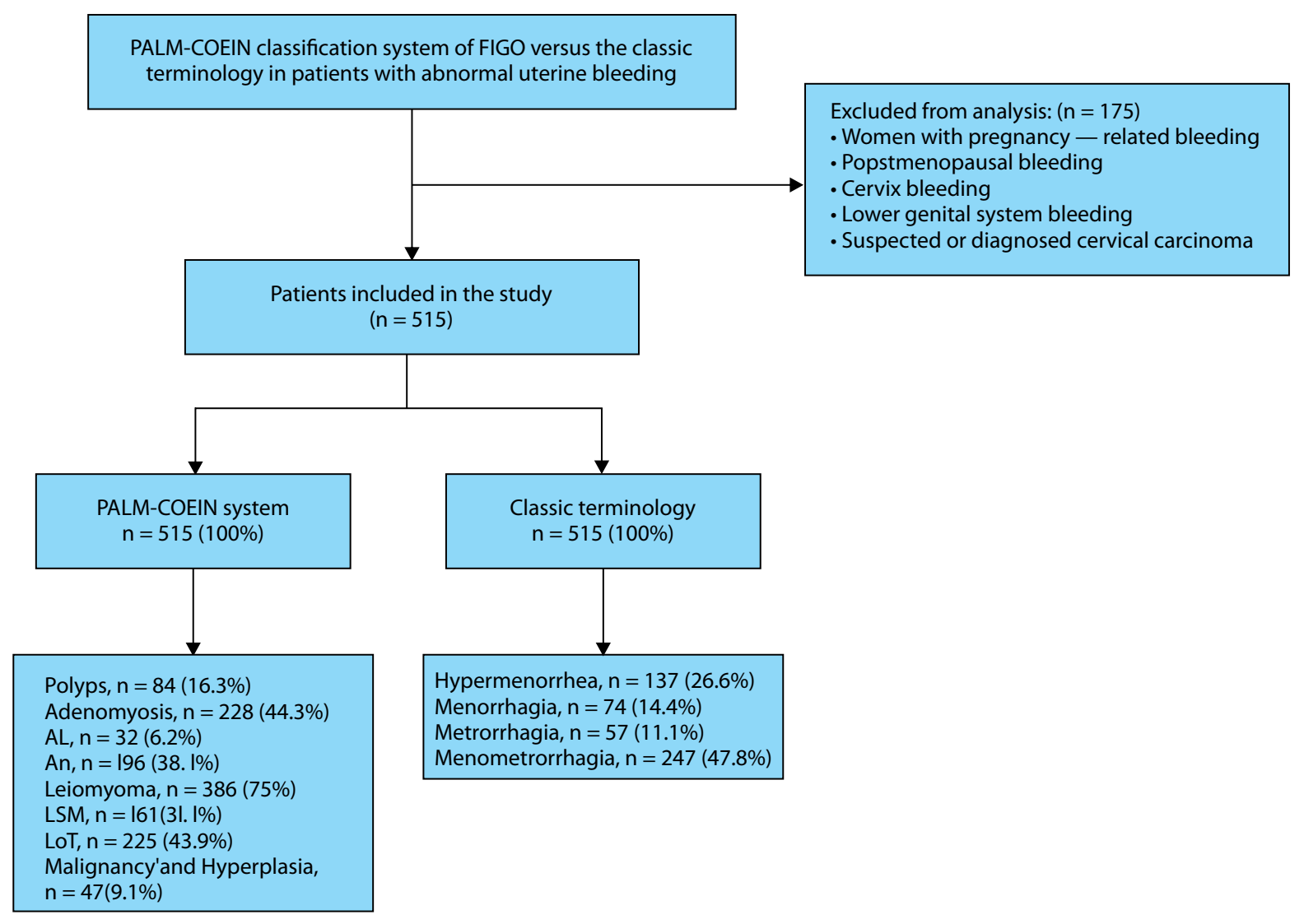

Figure 1. Study flowchart; AUB — abnormal uterine bleeding; PALM-COEIN — Polyp Adenomyosis Leiomyoma Malignancy and hyperplasiaCoagulopathy Ovulatory dysfunction Endometrial latrogenic Not yet classified; AL — local adenomyosis; AD — diffuse adenomyosis; LOT — others leiomyoma; LSM — submucous leiomyoma

\begin{tabular}{|c|c|c|c|c|}
\hline PALM-COEIN system & $\begin{array}{l}\text { Hypermenorrhea } \\
(n=137)\end{array}$ & $\begin{array}{l}\text { Menorrhagia } \\
(n=74)\end{array}$ & $\begin{array}{l}\text { Metrorrhagia } \\
(n=57)\end{array}$ & $\begin{array}{l}\text { Menometrorrhagia } \\
(n=247)\end{array}$ \\
\hline Polyp $(n=84)$ & $23(16.8)$ & $12(16.2)$ & $10(17.5)$ & $39(15.8)$ \\
\hline $\begin{array}{l}\text { Adenomyosis } \\
A_{L}(n=32) \\
A_{D}(n=196)\end{array}$ & $\begin{array}{l}2(1.5) \\
62(45.3)\end{array}$ & $\begin{array}{l}21(28.4) \\
4(5.4)\end{array}$ & $\begin{array}{l}2(3.5) \\
17(29.8)\end{array}$ & $\begin{array}{l}7(2.8) \\
112(45.3)\end{array}$ \\
\hline $\begin{array}{l}\text { Leiomyoma } \\
L_{S M}(n=161) \\
L_{O T}(n=225)\end{array}$ & $\begin{array}{l}30(21.9) \\
74(54.0)\end{array}$ & $\begin{array}{l}45(60.8) \\
7(9.5)\end{array}$ & $\begin{array}{l}20(35.1) \\
20(35.1)\end{array}$ & $\begin{array}{l}66(26.7) \\
124(50.2)\end{array}$ \\
\hline $\begin{array}{l}\text { Malignancy and } \\
\text { Hyperplasia }(n=47)\end{array}$ & $15(10.9)$ & $9(12.2)$ & $7(12.3)$ & $17(6.9)$ \\
\hline
\end{tabular}

PALM-COEIN — Polyp Adenomyosis Leiomyoma Malignancy and hyperplasia-Coagulopathy Ovulatory dysfunction Endometrial latrogenic Not yet classified; $A_{L}-{ }_{\text {local }}$ adenomyosis; $A_{D}$ - diffuseadenomyosis; $L_{O T}$ - others leiomyoma; $L_{S M}$ - submucous leiomyoma; ${ }^{\text {Values are given as number (percentage) }}$

\section{DISCUSSION}

This study was conducted to identify the reasons of AUB based on the PALM-COEIN classification and to compare the clinical and histopathological features to determine the definitive etiology for proper management of the AUB. As the clinical classification of AUB may result in inadequate treatment, there is a need for classification of the etiol- ogy. In this study, the histopathological result of the hysterectomy specimen was accepted as the gold standard to evaluate the accuracy of the preoperative diagnosis of AUB causes. "Dysfunctional uterine bleeding (DUB)" is now a useless term as women classified in this category in the past in fact fall into the FIGO categories of a varying combination of coagulopathy, disorder of ovulation, or endometrial 


\begin{tabular}{|l|l|}
\multicolumn{2}{|l|}{ Table 2. Subclassification of leiomyomas by location } \\
\hline Leiomyoma subclassification, $\mathbf{n}(\%)$ & $\mathbf{n}=\mathbf{3 8 6}(\mathbf{1 0 0})$ \\
\hline $\begin{array}{l}\text { Submucosal } \\
0\end{array}$ & $2(0.5)$ \\
1 & $5(1.3)$ \\
2 & $58(15.5)$ \\
\hline Other & \\
3 & $24(5.9)$ \\
4 & $191(50.4)$ \\
5 & $54(13.9)$ \\
6 & $10(2.4)$ \\
7 & $13(2.9)$ \\
8 & $5(1.1)$ \\
\hline Hybrid leiomyomas & \\
$2-5$ & $24(6.1)$ \\
\hline
\end{tabular}

ancluded in both the endometrium and serosa

pathologies considered as "unrelated to uterine structural abnormalities" [13].

Obesity has been proven to be one of the leading causes for AUB. Life-long exposure to estrogen by peripheral aromatization of adrenal androgens rises the incidence of polyps, leiomyomas and endometrial carcinomas in obese women (relative risk 3-10\%) [14]. In the present study, the mean BMI of the patients was found to be in the overweight category. Therefore, care should be taken in terms of AUB in obese women.

Endometrial polyps are one of the most common etiologies of AUB in both premenopausal and postmenopausal women. Although they may also be asymptomatic, the part of polyps to AUB varies between $3.7 \%$ and $65 \%$ [15]. Intermenstrual bleeding is the most frequent symptom in premenopausal women with endometrial polyps [16]. In the present study, $16.3 \%$ of women with AUB were found to have polyps and most had menometrorrhagia.

Uterine adenomyosis is a histological diagnosis based on the pathology evaluation of the uterus after hysterectomy. Preoperatively, the diagnosis is suggested by characteristic clinical manifestations (HMB and dysmenorrhea with a uniformly enlarged uterus), and a clinical diagnosis can be made with transvaginal ultrasound or magnetic resonance imaging findings. In some studies, the rate of adenomyosis as the cause of AUB has been reported as $14.5 \%-15.4 \%[13,17]$. In the present study, $44.3 \%$ of the women with AUB were found to have adenomyosis and most had menometrorrhagia. The higher rate of adenomyosis compared to literature was attributed to the high parity of the current study patients.

Uterine leiomyomas (fibroids or myomas) are common benign tumors. The most common presenting symptoms of uterine fibroids are heavy or prolonged menstrual bleeding. It was the most common cause of AUB followed by adenomyosis [13]. Myomas are clinically apparent in ap- proximately $12-25 \%$ of reproductive-age women and are noted on pathological examination of approximately $80 \%$ of surgically excised uteri [18]. In a recent study of patients with AUB, $26.7 \%$ of fibroids were found to be submucosal [17]. The factor most contributing to bleeding in the PALM group is fibroids. In the present study, $75 \%$ of the patients had fibroids according to the pathology results and $16.8 \%$ were submucous myoma. It was observed that submucosal type caused more AUB compared to intramural and subserous types [19]. It has been thought that submucous fibroids distort the cavity and are more likely to cause HMB [20]. In the current study, fibroids were classified into subgroups according to the PALM-COEIN classification.

The endometrium may develop endometrial hyperplasia, which includes non-neoplastic entities characterized by a proliferation of endometrial glands of irregular size and shape, and precancerous neoplasms characterized by neoplastic features but without invasion. Endometrial hyperplasia and malignancies typically present with AUB. Therefore, endometrial sampling is still the primary diagnostic method for AUB. In the present study, endometrial hyperplasia was seen in $9.1 \%$ of cases, similar to the findings of the Mishra and Sultan study [21].

Treatment of acute AUB depends on many conditions, such as clinical stability, pain, suspected bleeding etiology, future fertility desire, and underlying medical issues. There are two basic purposes of managing acute AUB, firstly to control the current heavy bleeding attack and then to decrease blood loss during menstrual cycles. The preferred initial treatment is medical treatment, and hormonal management is the first application to be considered. There are treatment options such as IV conjugated estrogen, oral progestins and combined oral contraceptives. However, some conditions may require immediate surgical treatment. If we look at the surgical options for example dilatation and curettage, endometrial ablation, uterine artery embolization and hysterectomy can be considered [22].

\section{CONCLUSIONS}

AUB is a complex condition because there are differences between individuals, so many pathologies accompany it. It can be considered that the use of the PALM-COEIN system will help eliminate confusion about the etiology of AUB and this diagnostic will enable more effective communication with other healthcare professionals, thereby resulting in better management of treatment.

\section{Acknowledgements}

The authors would like to thank Selen Begüm Uzun for assistance with the statistics used in this article.

\section{Conflict of interests}

The authors declare that they have no conflict of interests. 


\section{REFERENCES}

1. ACOG committee opinion no. 557: Management of acute abnormal uterine bleeding in nonpregnant reproductive-aged women. Obstet Gynecol. 2013; 121(4): 891-896, doi: 10.1097/01. AOG.0000428646.67925.9a, indexed in Pubmed: 23635706.

2. Harlow SD, Campbell OMR. Epidemiology of menstrual disorders in developing countries: a systematic review. BJOG. 2004; 111(1): 6-16, doi: 10.1111/j.1471-0528.2004.00012.x, indexed in Pubmed: 14687045.

3. Munro MG, Critchley $\mathrm{H}$, Fraser IS. Research and clinical management for women with abnormal uterine bleeding in the reproductive years: More than PALM-COEIN. BJOG. 2017; 124(2): 185-189, doi: 10.1111/14710528.14431, indexed in Pubmed: 28012269.

4. Madhra M, Fraser IS, Munro MG, et al. A five-year international review process concerning terminologies, definitions, and related issues around abnormal uterine bleeding. Semin Reprod Med. 2011; 29(5): 377-382, doi: 10.1055/s-0031-1287661, indexed in Pubmed: 22065324.

5. Fraser IS, Critchley HOD, Munro MG, et al. Can we achieve international agreement on terminologies and definitions used to describe abnormalities of menstrual bleeding? Hum Reprod. 2007; 22(3): 635-643, doi: 10.1093/humrep/del478, indexed in Pubmed: 17204526.

6. Munro MG, Critchley HOD, Broder MS, et al. FIGO Working Group on Menstrual Disorders. FIGO classification system (PALM-COEIN) for causes of abnormal uterine bleeding in nongravid women of reproductive age. Int J Gynaecol Obstet. 2011;113(1): 3-13, doi: 10.1016/j.ijgo.2010.11.011, indexed in Pubmed: 21345435.

7. Sharma JB, Yadav M. New ground breaking International Federation of Gynecology and Obstetrics's classification of abnormal uterine bleeding: Optimizing management of patients. J Midlife Health. 2013; 4(1): 42-45, doi: 10.4103/0976-7800.109637, indexed in Pubmed: 23833534.

8. Bahamondes $\mathrm{L}$, Ali M. Recent advances in managing and understanding menstrual disorders. F1000Prime Rep. 2015; 7: 33, doi: 10.12703/P7-33, indexed in Pubmed: 25926984.

9. Mohammed N, Prejisha BA. study of correlation of etiological and histopathological findings in females undergoing hysterectomy for abnormal uterine bleeding - in accordance with PALM-COEIN classification. Paripex Indian J Res. 2014; 3(11): 76-77.

10. Khrouf M, Terras K. Diagnosis and Management of Formerly Called “Dysfunctional Uterine Bleeding" According to PALM-COEIN FIGO Classification and the New Guidelines. J Obstet Gynaecol India. 2014; 64(6): 388-393, doi: 10.1007/s13224-014-0641-1, indexed in Pubmed: 25489140.
11. Gordts S, Brosens JJ, Fusi L, et al. Uterine adenomyosis: a need for uniform terminology and consensus classification. Reprod Biomed Online. 2008; 17(2): 244-248, doi: 10.1016/s1472-6483(10)60201-5, indexed in Pubmed: 18681999.

12. Munro MG, Critchley HOD, Fraser IS, et al. FIGO Menstrual Disorders Working Group. The FIGO classification of causes of abnormal uterine bleeding in the reproductive years. Fertil Steril. 2011;95(7): 2204-8, 2208. e1, doi: 10.1016/j.fertnstert.2011.03.079, indexed in Pubmed: 21496802.

13. Qureshi FU, Yusuf AW. Distribution of causes of abnormal uterine bleeding using the new FIGO classification system. JPMA. 2013; 63(973).

14. Nouri M, Tavakkolian A, Mousavi SR. Association of dysfunctional uterine bleeding with high body mass index and obesity as a main predisposing factor. Diabetes Metab Syndr. 2014; 8(1): 1-2, doi: 10.1016/j. dsx.2013.10.013, indexed in Pubmed: 24661749.

15. Whitaker L, Critchley HOD. Abnormal uterine bleeding. Best Pract Res Clin Obstet Gynaecol. 2016; 34: 54-65, doi: 10.1016/j.bpobgyn.2015.11.012, indexed in Pubmed: 26803558.

16. Hassa $H$, Tekin $B$, Senses $T$, et al. Are the site, diameter, and number of endometrial polyps related with symptomatology? Am J Obstet Gynecol. 2006; 194(3): 718-721, doi: 10.1016/j.ajog.2005.08.060, indexed in Pubmed: 16522403.

17. KARAKAYA BK, SERT Ü, IBANOĞLU M, et al. Evaluation of PALM-COEIN Classification with Abnormal Uterine Bleeding in Turkish Women. Türk Üreme Tibbi ve Cerrahisi Dergisi. 2018; 2(3): 81-85, doi: 10.24074/tjrms.2018-61956.

18. Downes E, Sikirica V, Gilabert-Estelles J, et al. The burden of uterine fibroids in five European countries. Eur J Obstet Gynecol Reprod Biol. 2010; 152(1): 96-102, doi: 10.1016/j.ejogrb.2010.05.012, indexed in Pubmed: 20598796.

19. Malhotra N, Kumar P, Malhotra J, et al. Jeffcoate $+39+s$ Principles of Gynaecology. 2014, doi: 10.5005/jp/books/12185.

20. Munro MG. Classification of menstrual bleeding disorders. Rev Endocr Metab Disord. 2012; 13(4): 225-234, doi: 10.1007/s11154-012-9220-x, indexed in Pubmed: 22851041.

21. Mishra D, Sultan S. FIGO's PALM-COEIN Classification of Abnormal Uterine Bleeding: A Clinico-histopathological Correlation in Indian Setting. J Obstet Gynaecol India. 2017; 67(2): 119-125, doi: 10.1007/s13224-0160925-8, indexed in Pubmed: 28405119.

22. National Institute for Health and Care Excellence (UK). Heavy menstrual bleeding (update). NICE Guideline. 2018, No. 88. 